\title{
Hans-Karl Wiegandt e a introdução da litografia na província do Gram-Pará em 1870
}

\author{
Hans-Karl Wiegandt and the outset of lithography printing in the \\ province of Gram-Pará in 1870
}

MARTINS, Fernanda de O.

Grupo SER/UNAMA I fernandaforminform@gmail.com

LIMA, Edna Lucia O. da Cunha

Pontifícia Universidade Católica do Rio de Janeiro - PUC- Rio

ednacunhalima@gmail.com

LIMA, Guilherme Cunha

Universidade do Estado do Rio de Janeiro - ESDI I gecunhalima@globo.com

\begin{abstract}
Resumo
Este artigo se insere em pesquisa sobre a história da tipografia no Pará e apresenta o litógrafo Hans-Karl Wiegandt. Para tanto foram realizadas extensas pesquisas bibliográficas e documentais em instituições no Rio de Janeiro e no Pará. A técnica de impressão litográfica que permite a impressão de texto e imagem concomitantemente foi importante para nosso país nos momentos conturbados que antecederam a República. No caso do Pará, Wiegandt foi não apenas o primeiro litógrafo local como difundiu a técnica a seus contemporâneos, sendo responsável pelo cenário de jornais ilustrados que circularam no período e a farta utilização das imagens impressas em jornais, revistas, rótulos, embalagens. Os impressos ilustrados colaboraram para a construção dos ideais da modernidade. Espera-se com este artigo colaborar para o entendimento da do design no Brasil, ao voltarse especialmente em regiões pouco estudadas.
\end{abstract}

Palavras Chave: História do design. História da tipografia. Memória gráfica brasileira. Pará.

\section{Abstract}

This paper is part of a research on the history of typography in Pará and presents the lithographer HansKarl Wiegandt. In order to achieve that, extensive bibliographical and documentary researches were carried in institutions in Rio de Janeiro and Pará. The lithographic technique (which allows the printing of text and image simultaneously) was important for our country in the troubled times that preceded the Republic establishment. In Pará, Wiegandt was not only the first local lithographer, but also diffused the technique to his contemporaries, being responsible for the illustrated newspapers in publication during the period and the extensive use of images printed in newspapers, magazines, labels and packaging. The illustrated printings collaborated to the construction of modernity ideals. This paper aims to improve the understanding of design in Brazil, especially in regions where few studies were conducted.

Keywords: Design. Design history. History of typography. Brazilian graphic memory. Pará. 


\section{INTRODUC̣ÃO}

Este artigo se insere no âmbito das pesquisas realizadas sobre a introdução e desenvolvimento das técnicas de impressão na Província do Gram-Pará no século XIX, e aqui, mais especificamente, volta-se ao momento da introdução das técnicas litográficas.

A Província do Grão-Pará, está entre as cinco primeiras províncias a contar com uma tipografia. Sua a primeira oficina, construída por João Francisco Madureira, iniciou seus trabalhos em 1821. Em relação à litografia, técnicas de reprodução simultânea de texto e imagem, apesar de chegarem relativamente cedo à Corte do Rio de Janeiro, estas demoraram a sem instaladas nas províncias e chegando à região apenas em 1870. Comparativamente, o Rio de Janeiro conhecia a litografia desde a chegada de Palliére em 1817, seguida da instalação da litografia do Arquivo Militar em 1822. Na Bahia a litografia chegou em 1845 e, em Recife, em 1861. Ainda foram necessários nove anos a partir da instalação no Recife para a introdução da litografia no Pará.

Os eventos turbulentos que ocorreram na região entre a adesão à Independência do Brasil e a Abertura dos Portos da Amazônia em 1850, incluindo diversos surtos epidêmicos, retardaram o desenvolvimento econômico da região. A navegação comercial pelos rios amazônicos, autorizada em 1853, se deu efetivamente em 1867, após a assinatura do decreto de 7 de dezembro de 1866 que determina a abertura dos Portos da Amazônia às nações amigas. A capital da província, Belém, em função de sua situação geográfica, é a porta de entrada de produtos importados e de saída dos produtos exportados. Torna-se um importante centro comercial.

O crescimento econômico da Amazônia, decorrente da elevação dos preços da borracha nesse período, somado às políticas governamentais de estímulo a imigração influenciaram a chegada de muitos estrangeiros à região. Grande parte desembarca para trabalhar em projetos de desenvolvimento agrícola, formando colônias rurais. Outros, profissionais especializados ou pequenos comerciantes, chegam de forma independente e instalam-se nas cidades iniciando novos negócios. Trazem em sua bagagem, técnicas, tecnologias e uma visão de mundo de sua experiência de vida europeia ou de outras regiões, que vem de encontro às necessidades da província que se moderniza.

Nesse cenário ocorre a implantação da primeira oficina litográfica local, em 1870, com a chegada do litógrafo Hans-Carl Wiegandt, também chamado 
de Carlos Wiegandt ou João Carlos Wiegandt, nascido em vinte e nove de abril de 1841 em Colônia, atual Alemanha (SALLES, 1992)1.

Para compreender a produção de impressos no Pará no século XIX lançamos mão de alguns métodos tradicionais da historiografia, como a pesquisa bibliográfica e a pesquisa documental em acervos. Iniciamos com um levantamento bibliográfico em livros de cronistas da época, alguns ainda em tempo de ser testemunhas oculares dos fatos, assim como na bibliografia existente, livros e pesquisas acadêmicas. Dedicamos nossa atuação tanto à história do Pará quanto às pesquisas e publicações voltados à imprensa.

A pesquisa bibliográfica foi acompanhada da pesquisa documental realizada em instituições do Rio de Janeiro como a Biblioteca Nacional (BN), o Arquivo Nacional (AN) e o Instituto Histórico e Geográfico do Brasil (IHGB); e do Pará, como o Arquivo Público do Estado do Pará (APEP), o Museu da Universidade do Federal do Pará (MUFPA), a Biblioteca Pública do Estado do Pará (BPEP), a Biblioteca do Theatro da Paz (BTP), o Centro de Memória da Universidade do Federal do Pará (CEMUFPA) e a Junta Comercial do Estado do Pará (JUCEPA). Em relação ao Grêmio Literário Português, em Belém, foi realizada apenas pesquisa dos títulos existentes em seu acervo.

Em se tratando de pesquisa em acervos não é possível deixar de citar o importante legado deixado pelo pesquisador Vicente Salles, cujo acervo hoje encontra-se depositado no Museu da Universidade Federal do Pará. Salles realizou densa pesquisa sobre a caricatura no Pará se tornando fonte fundamental neste trabalho.

\section{A INTRODUC̣ÃO DA OFICINA LITOGRÁFICA NO GRAM-PARÁ}

De acordo com o historiador Vicente Salles (1994), Wiegandt chegou ao Brasil por volta de 1868, com cerca de 27 anos de idade, vindo a falecer em Belém em 1908. Estabeleceu-se, inicialmente, em Recife, onde, segundo Alfredo de Carvalho (1908), lançou o jornal caricato "A Careta", juntamente com o litógrafo W. de Melo Lins. Já na edição de 21 de outubro de 1869 do Jornal do Recife (fig.1), encontramos uma nota de Melo e Lins informando aos interessados o desaparecimento do sócio. Em seguida, em novo anúncio o mesmo Melo e Lins trata de se defender de cobranças sobre edições anteriores. Identifica-se desta maneira a data de sua partida para o Pará.

Segundo Carvalho (1908), a edição inicial d'A Careta é de 2 de julho de 1869, e a última publicada em 20 de dezembro de 1869. Referente a sua

1 Coleção de artigos publicados entre 28 jun. 1992 a 1 jan. 1994 no jornal A Província do Pará, localizados no Museu de Universidade Federal do Pará. 
permanência em Recife, a publicação da faculdade de Direito "Ilustração Acadêmica" de junho de 1869 (fig. 2), encontrada nos arquivos da Biblioteca Nacional, apresenta na capa a indicação Lith. Mello Lins \& CW. Cia Pern. Co. Na capa ainda vemos uma assinatura Wiegdt e nas demais ilustrações a rubrica CW. Uma análise da edição nos mostra bustos de pessoas falecidas em março e abril do mesmo ano. É possível afirmar que ele ali chegara antes de junho daquele ano.

Figura 1 - Anúncio no Jornal do Recife, de 21 de outubro de 1869.

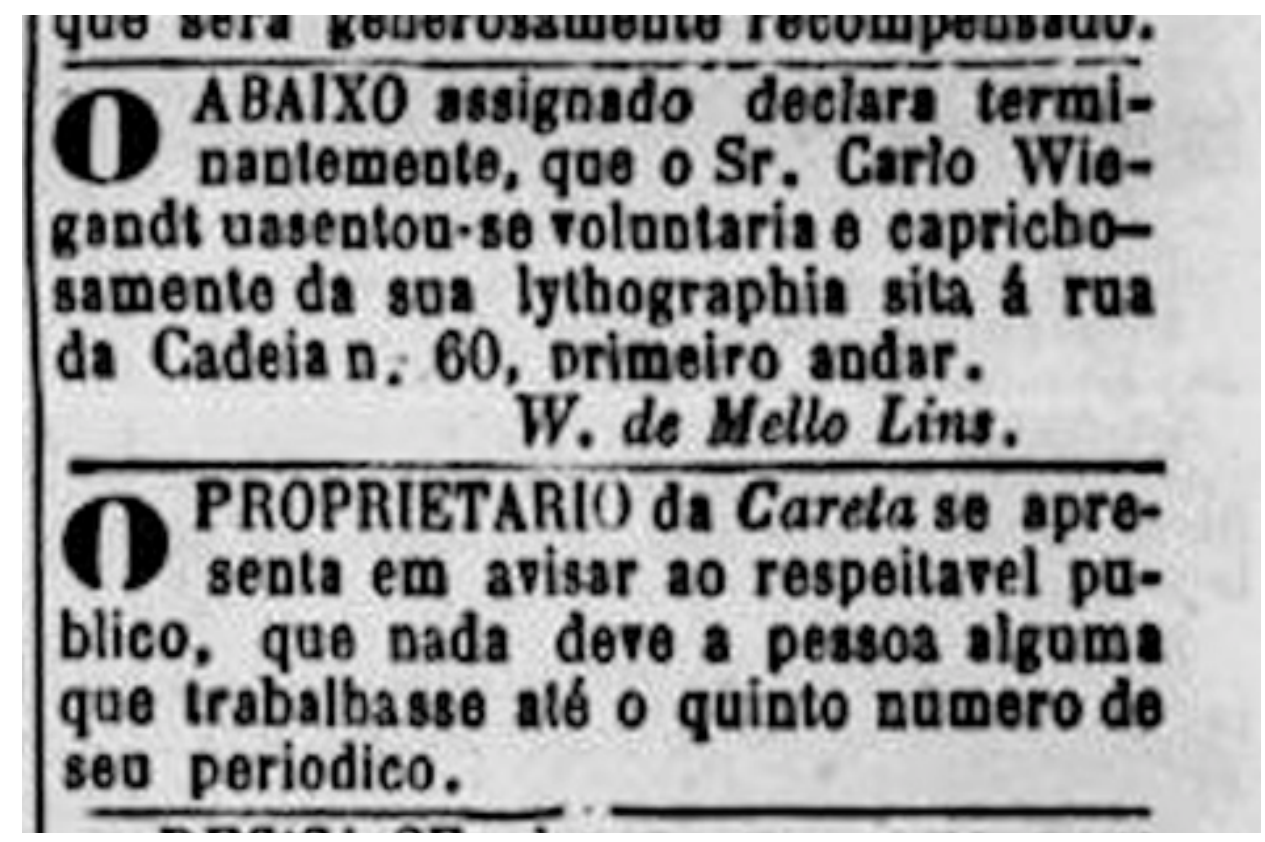

Fonte: Biblioteca Nacional.

A vinda de Wiegandt a Belém marca uma nova fase para a história gráfica da província, tendo permitido o surgimento da imprensa ilustrada através da litografia. Sua atuação, como veremos a seguir, seja como litógrafo, seja como empresário, foi fundamental para o desenvolvimento da indústria gráfica paraense. É possível identificar anúncios oferecendo esse tipo de serviço em jornais de anos anteriores a sua chegada, mas devido ao fato de não existirem empresas registradas com esse ofício ou mesmo indicações de litografias operando nos almanaques da época, entende-se que não eram realizadas localmente.

Orlando da Costa Ferreira (1976, p. 240) situa a empresa litográfica de Wiegandt no ano de 1877, a partir da publicação de "O Postilhão", do qual não encontramos exemplares. Sabemos que, em 1878 publica o semanário dominical "O Puraqué", um conjunto de ilustrações caricatas anônimas de cunho republicano, com unidade estilística creditada ao artista. 
Figura 2 - Capa da Illustração Acadêmica, trabalho de Wiegandt em Recife, 1869.

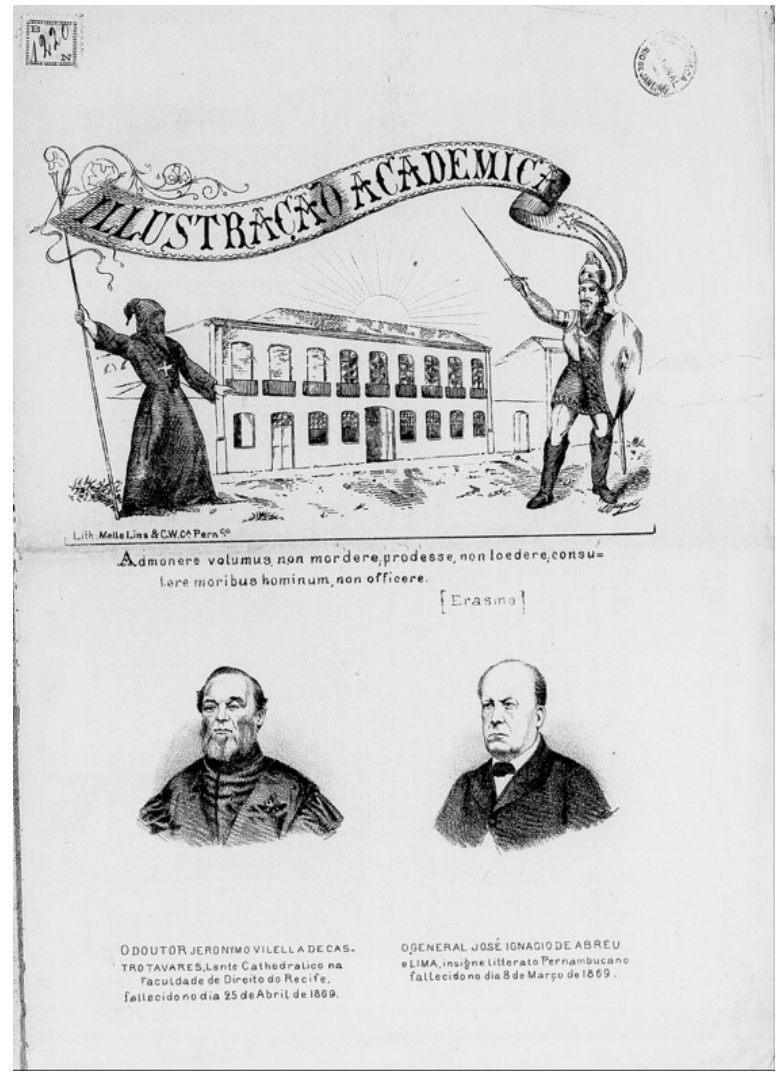

Fonte: Biblioteca Nacional.

Figura 3 - O Puraqué, 1878.

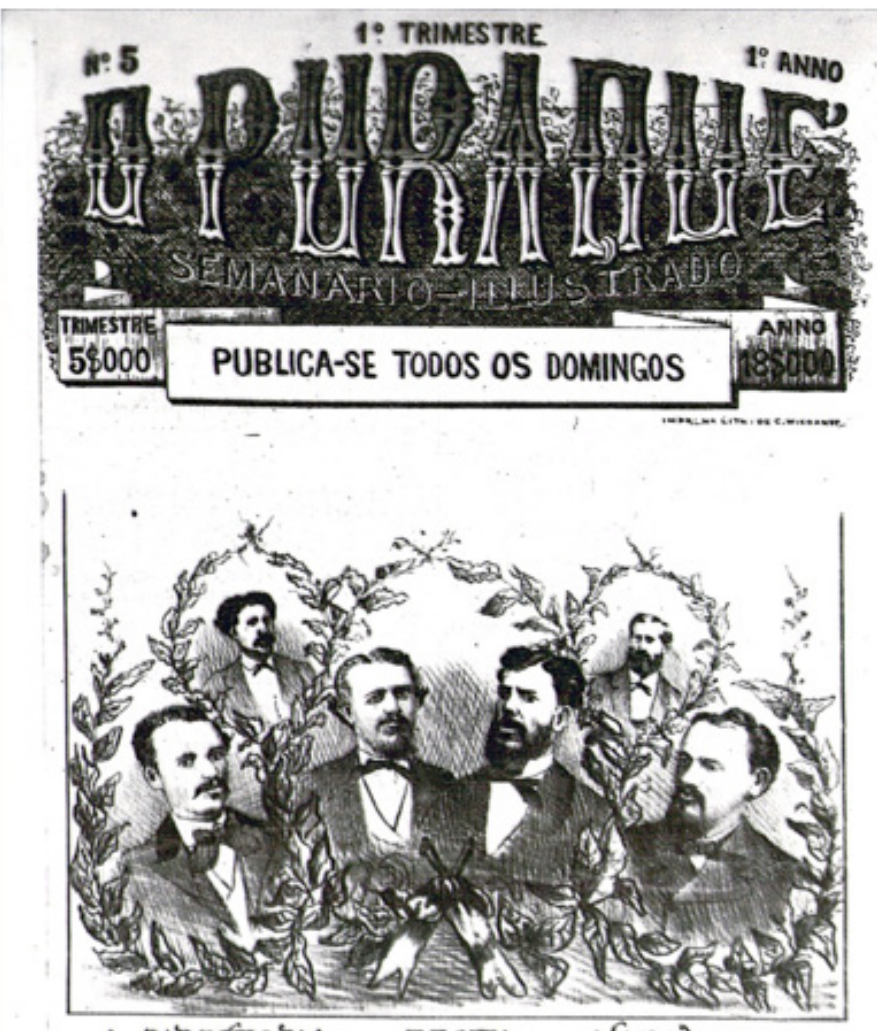

ADIRECTORIA, dd.FESTA de NAZARETH. A pedido do Bis Nose de 2 do corremte.

Fonte: Imagem cedida por Nathan Levi. 
No entanto, é possível afirmar que em 1871 a litografia local já se encontrava em operação na província. Uma estampa de Jeronimo Francisco Coelho assinada por Lith Wiegandt - Pará (figura 4) encontra-se no Almanak Administrativo, Mercantil e Industrial publicado por Carlos Seidl em 1871. Ao que tudo indica, esta é a mais antiga imagem litografada pelo artista executada e publicada no Pará, sendo, portanto, o marco fundador da utilização da litografia na Província.

Figura 4 - Imagem litográfica representando o Presidente da Província Jerônimo Coelho, realizada por Carlos Wiegandt

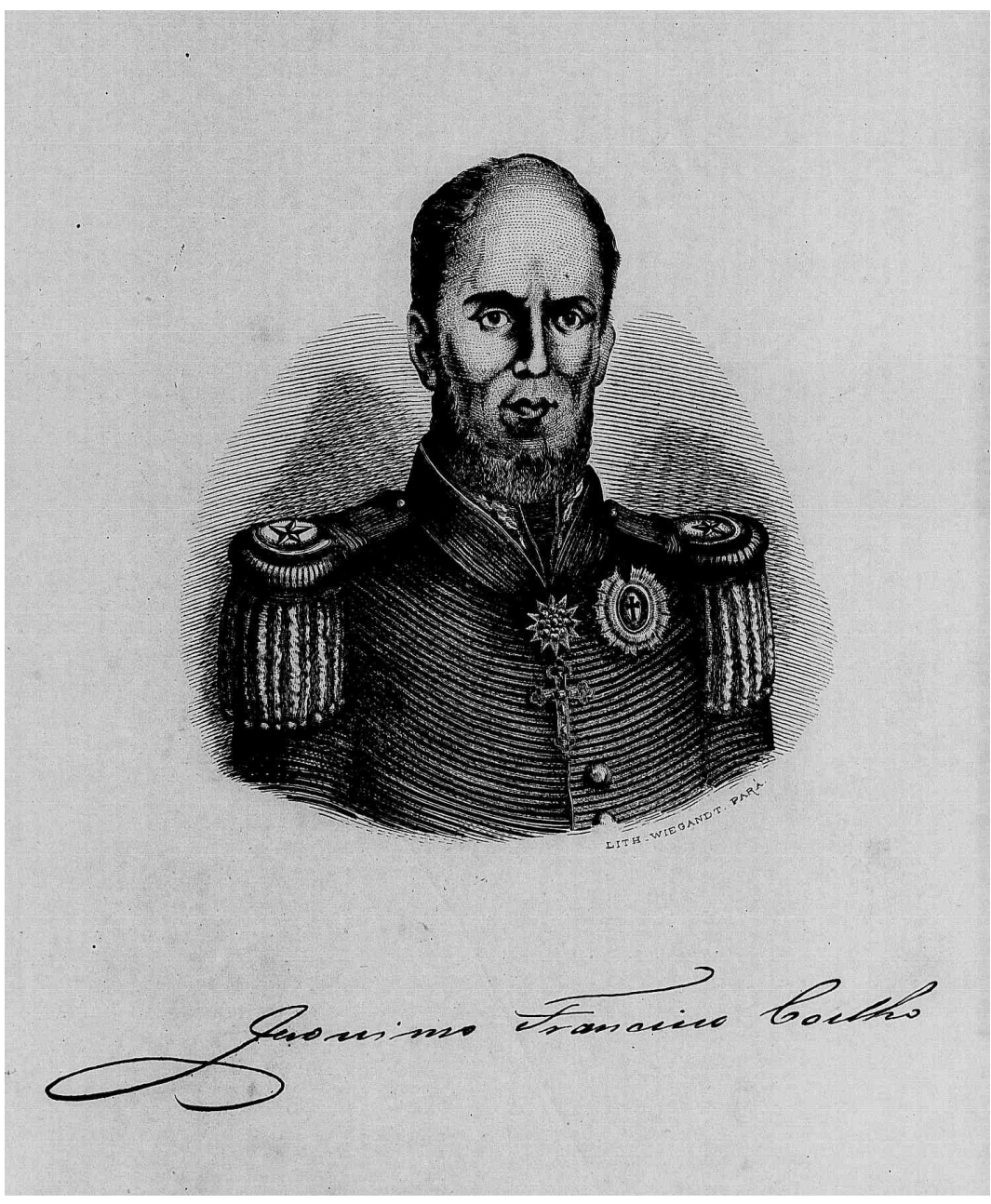

Fonte: Almanaque Industrial de 1871 (BIBLIOTECA NACIONAL DIGITAL BRASIL, 2013).

Em seu livro de 1895 Exposição Artística e Industrial de Lyceu Benjamin Constant, Ignacio Moura relata a entrevista que realizou com o artista, em sua própria oficina. Àquela época, o litógrafo também possuía uma marmoraria tendo se tornado, assim, um empresário importante. O ambiente é profissional, segundo o autor, que nos relata a presença de artistas silenciosos, ouvindo-se o tilintar do martelo no escopo. Segue o depoimento de Wiegandt:

Fundei minha lithographia no anno de 1871, impellido por uma indiscritível força de vontade e capricho, luctando com inumares [sic] dificuldades, não só pela falta de 
recursos pecuniários como também por ser uma arte pouco conhecida no Pará, por não a julgarem necessária. Tive uma pedrinha lithographica, abrindo as gravuras com agulha de costura e laminas de canivetes. Imprimia com um rolo de ferro e um pano de borracha. A tinta era de typographia engrossada com resina e depois de passado um tempo. Com trabalho e economia pude adquirir um pequeno prelo e mais tres pedrinhas e assim pude abrir ao publico a minha pequena oficina litographica no ano de 1871. Actualmente o estabelecimento litographico está nas condições de concorrer com outro qualquer estabelecimento congénere, artística e technicamente. Possui um pessoal habilitado em todas as especialidades concernentes a lythographia como sejam: desenho, gravura, pintura e impressão de papeis commerciaes, papeis de valor. tais como letras, acções, apolices, cheques, notas de Banco, etc; cartazes, anúncios, rotulos, etiquetas para pharmacias, impressos em chromolytographia para fabricas industriaes, diplomas, patentes, estampas em todos os generos, mappas geographicos, impressos de desenhos architetonicos, artísticos e scientíficos. O estabelecimento trabalha com trez prélios rapidos movidos por um vapor de seis atmosferas, quatro prélos manuais, dois de cortar e um de perfurar. Outras machinas estão encommendadas. Assim trabalhará com milhares de pedras litographicas de todos os formatos. O pessoal compôe-se de seis impressores, sendo trez nacionaes e e trez extrangeiros: um encadernador um cortador de papeis, dous limpadores de pedras e seis ajudantes, todos nacionaes. $\mathrm{O}$ atelier litographico trabalha com duas machinas de quilgochoar e um pautographo gravador do systema mais aperfeiçoado. Tem mais cinco lythographos, sendo um nacional e quatro estrangeiros (MOURA, 1895, p. 146-147).

Desta forma, pelo que nos confirma o próprio artista é 1871 a data da fundação de sua tipografia, e é muito provável que existam trabalhos anteriores ao retrato de Jerônimo Coelho para serem identificados.

O litógrafo, que começou com "uma pedrinha", logo formalizou sua empresa, cresceu, comprou máquinas e contratou funcionários, brasileiros e estrangeiros. Ampliou sua atuação até tornar-se proprietário da mais importante empresa gráfica da Amazônia - Estabelecimento Graphico C. Wiegandt - sendo um personagem de prestígio no cenário local. Pertenceu à Associação Tipográfica local em 1874, fez parte da primeira diretoria da Sociedade Propagadora de Ensino em 1891, e foi também professor da Escola Normal. Ganhou vários prêmios nas exposições locais e nacionais e, de acordo com Salles (1972, p. 22), foi o introdutor de outras técnicas gráficas, como a estereotipia e o clichê: 
Carlos Wiegandt, introdutor da litografia no Pará, não foi propriamente editor de música. Aparece como litógrafo e impressor. Enão são poucos os exemplares que conhecemos saídos do seu estabelecimento. Merece, pois, referência especial pelo pioneirismo e pelo nível técnico e estético de seus trabalhos. Cabe-lhe o papel de haver inaugurado no Pará a arte da litogravura e os trabalhos gerais de litografia. Seu atelier estava aparelhado com máquinas de quilgochoar e um pautógrafo gravador do sistema mais aperfeiçoado, onde trabalhavam 5 litógrafos, em 1895, sendo um nacional e 4 estrangeiros. O sistema conhecido pela designação calcografia - gravura sobre chapa metálica, principalmente cobre - e os mais modernos, como imagens ou dizeres em relevo, obtidos por estereotipia - o chamado cliché também foram introduzidos no Pará por Carlos Wiegandt. Depois de viver mais de 40 anos em Belém, aí faleceu, com avançada idade, em 1909.

Wiegandt tornou-se empresário em outras atividades, além da litografia. Aproveitando a utilização das pedras, fundou uma marmoraria, em sociedade com Karl Wirth (fig.5), executando serviços para particulares e para o governo. Além da obra do Cemitério de Santa Isabel, foi contratado para o projeto e execução de arco do triunfo que seria construído para receber o imperador quando de sua visita a província. Entretanto, não foi possível encontrar registros de que esta obra tenha sido realizada. No Diário de Belém de 1889 encontramos a notícia do falecimento de seu sócio, Wirth.

Figura 5 - Anúncio da empresa de mármores de Wiegandt e Wirth.

WIEGANDT \& W/RTH
Com officina de marmore
Estabelecidos na
TRAVESSI DR S. IHTHECS I. 20
Encarregam-se de toda e qualquer obra
feita em marmore, granito, ou qualquer
outra pedra,conıo sejam:nausoleos, monu-
mentos, urnas, altares, pias, chapas e
guarnições de marmores para mobilias,
ladrilhos de marmore, banheiros, e toda
ornamentação architetonica em pedra.
Encarregam-se tambem dos alicerces,
e subterraneos para mausuleos; fornecem
desenho em qualqaer estylo architectonico
respectivos orçamentos.
Garantem solidez e boa execução das
obras que lhes forem confiadas e tudo por
preços 0s mais modicos possiveis.

Fonte: Diário de Belém, 1886, Biblioteca Nacional. 
Segundo Salles (1972), Wiegandt encampou as instalações e os maquinários de Arthur Caccavoni e A. Campbell, além de empregar o operariado destes estabelecimentos - mão-de-obra altamente especializada em litografia, calcografia, tipografia, rotogravura etc. Passa a se denominar então, Empresa Gráfica Amazônia.

\subsection{Os Impressos Litografados}

Carlos Wiegandt foi seguramente o personagem mais importante da área gráfica do Pará no final do século XIX. Sua empresa evolui da litografia para outras especialidades gráficas, adquirindo novos equipamentos e se aprimorando tecnicamente. Sua obra em litografia é vasta e abrangente. Em 1877, realiza um de seus trabalhos mais importantes foi a publicação da Coleção "Vistas do Pará" em 1877, com desenhos do artista J. Leon Righini. Nota-se que seu proprietário cresceu sem se envolver na política partidária dos momentos iniciais da República. Pelo contrário, ao oferecer uma especialidade rara, manteve uma parceria permanente com outras empresas. Além da publicação em jornais, realizou, ainda, ilustrações científicas, certificados, bonds, libretos de música, livros e rótulos de produtos.

Figura 6 - 12 Vistas do Pará - Theatro da Paz, de Righini, Litografia de Wiegandt, 1877.

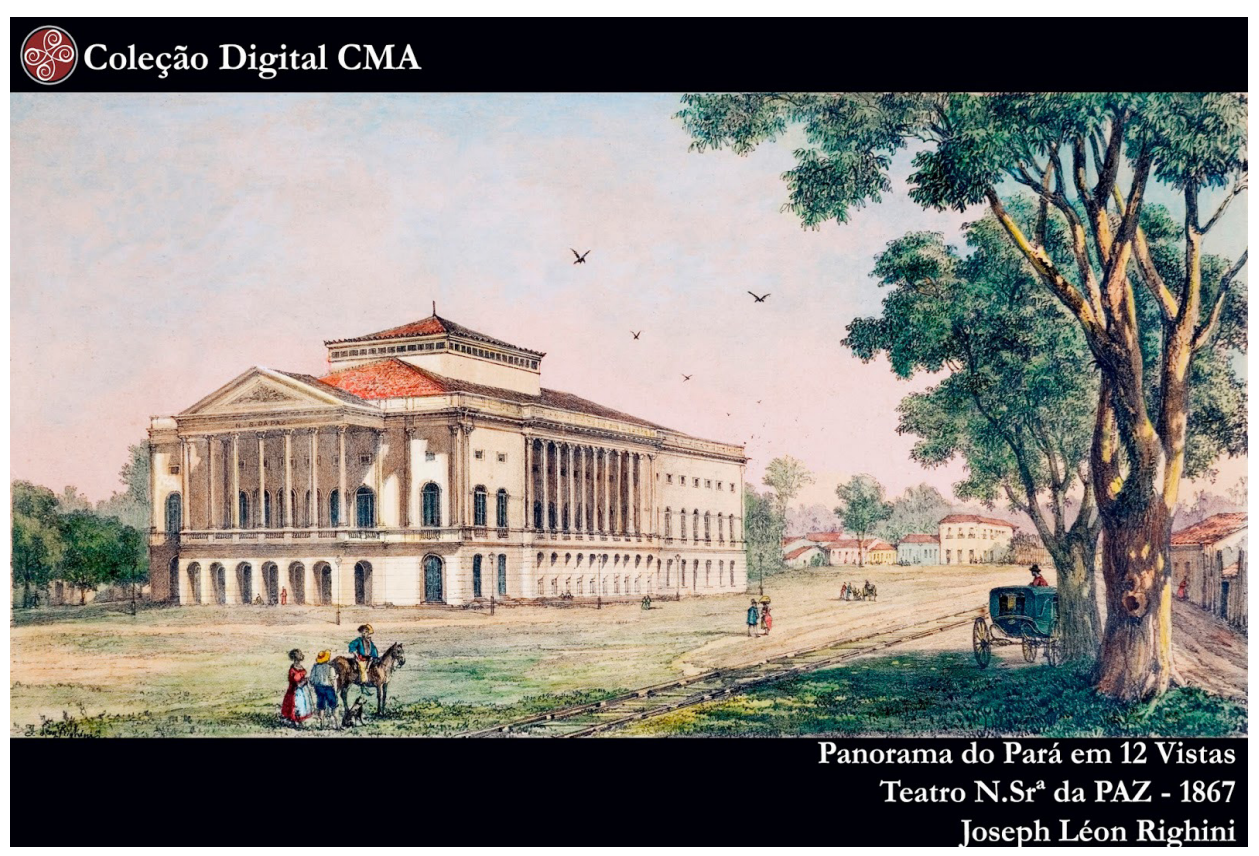

Fonte: Centro de Memória da Amazônia - UFPA.

A litografia favorece o aparecimento do jornal caricato, que teve um papel tão importante na época da transição do Segundo Reinado para a República e, sobretudo, para o início do fotojornalismo.

No Segundo Reinado, a introdução da técnica litográfica como processo de reprodução permitiu a atualização técnica, aumentando a escola de reprodução da página 
impressa, mas, sobretudo, facilitando a integração entre texto e imagem na composição gráfica, o que constituía um dos maiores desafios para a empresa gráfica da época. Além disso, a imprensa ilustrada também começou a publicar imagens baseadas em fotografias, lançando as bases para documentais da informação, próprias do fotojornalismo (KNAUSS, 2011, p. 12).

Figura 7 - Capa do Jornal A República, 1891.

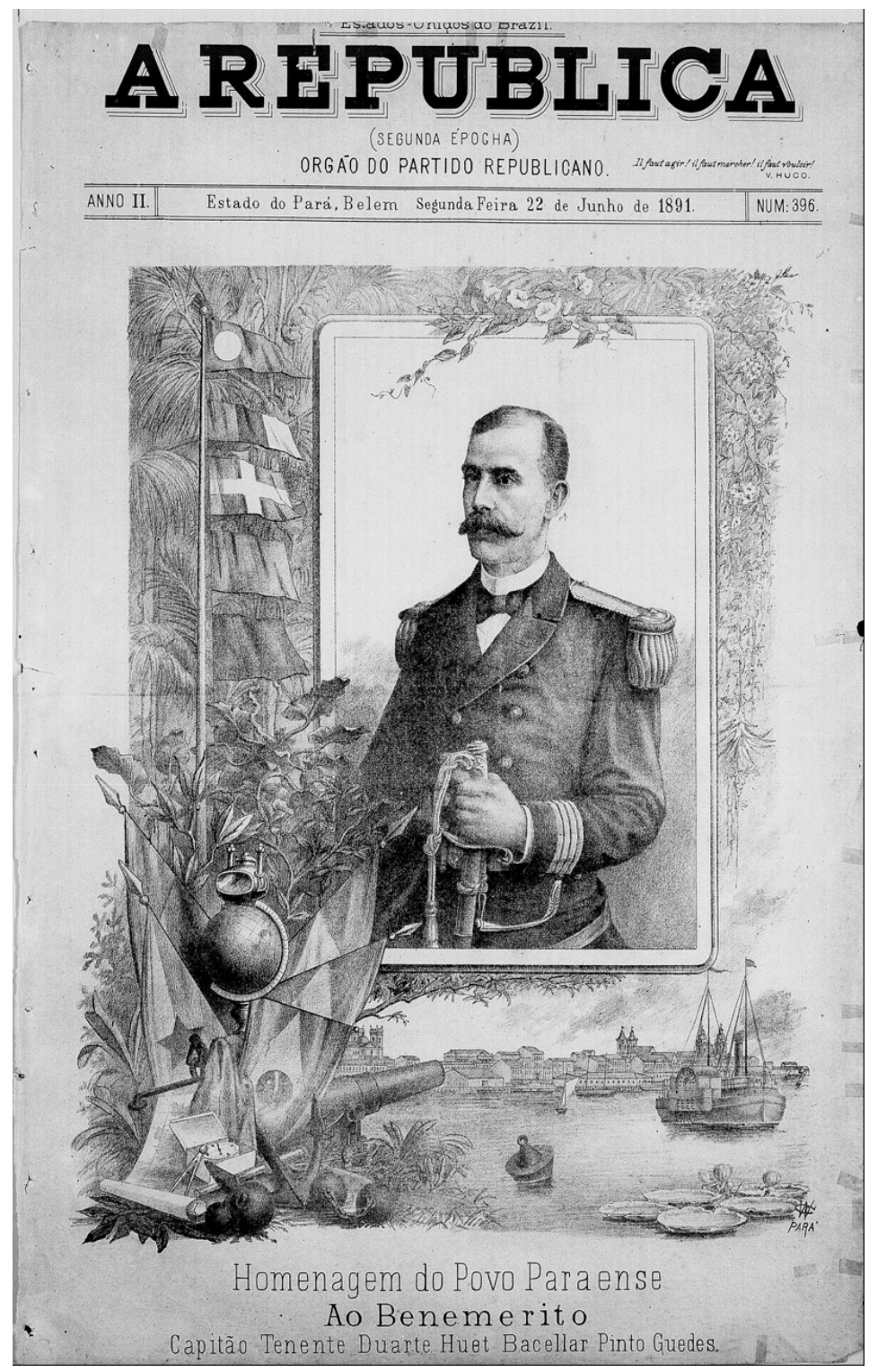

Fonte: Biblioteca Nacional.

\subsection{Wiegandt Impulsiona o Cenário da Litografia}

A importância de Wiegandt vai além de sua atuação profissional, além de trabalhar com estrangeiros, o litógrafo apoiou e formou muitos artistas locais. O pesquisador Vicente Salles publicou em jornais no Pará uma série de artigos sobre a caricatura, eram todos litógrafos. Com base nessa pesquisa, no acervo 
que se encontra hoje no Museu da Universidade Federal do Pará e em jornais do período, apresentamos a seguir alguns dos litógrafos paraenses. Muitos fizeram o aprendizado nas oficinas de Wiegandt e depois seguiram suas carreiras em outros estabelecimentos, como o pernambucano Crispim do Amaral, que chega a trabalhar no Rio de Janeiro e João Archibald Campbell que montou sua própria empresa.

O mulato pernambucano Crispim do Amaral (1856-1911) é talvez o produto mais extraordinário do legado de João Carlos Wiegandt na distribuição de seu conhecimento técnico e artístico. Foi em suas oficinas que o jovem Crispim iniciou, aos 18 anos de idade, a carreira de caricaturista que iria se consagrar em paris e culminar no Rio de Janeiro com a fundação de O Malho. [....] Irrequieto e genial, Crispim do Amaral marcou sua presença na caricatura brasileira, a partir de Belém do Grão-Pará. [...] Dois outros discípulos paraenses deixaram boa produção impressa nos jornais caricatos: Joao Archibald Campbell (1840-1924) e João Gomes Corrêa de Faria (1865-1898) (SALLES, 1994, p. 18)

Em relação aos estrangeiros, pode-se citar Ernst Löhse, que depois de trabalhar alguns anos na Casa Wiegandt, é contratado pelo Museu Paraense como litógrafo, impressor e ilustrador, executando trabalhos fundamentais na documentação científica (MUSEU PARAENSE EMILIO GOELDI, 1983). Crispim do Amaral, pernambucano, artista múltiplo, cenógrafo, ator, músico, veio para a Amazônia com 18 anos, engajado na companhia teatral de Vicente Pontes de Oliveira, entre 1876 e 1882, onde também atuaram seus irmãos, Manoel e Libânio. Este último instalou-se em Manaus como pintor e fotógrafo. Crispim do Amaral (PUK) e seu irmão Manoel do Amaral (DUCK) publicam em 18790 Estafeta (6/4/1879), de curta duração, litografado pela única oficina litográfica existente na época, a Casa Wiegandt. Em 1887 Crispim trabalha nas obras de decoração do Theatro da Paz e lança com o irmão a Semana llustrada em 1887, inicialmente impressa na tipografia do Livro do Povo e depois em oficina própria, tipográfica e litográfica. O periódico teve duas fases, a primeira durou dois anos e publicou 50 exemplares. A segunda fase durou dezesseis edições, sendo onze capitaneadas por Crispim e as seguintes pelo irmão, Manoel, que vende em 1888 a oficina para João Archibald Campbell. Em 1888 Crispim recebe prêmio do Governo da Província e viaja para Paris, onde é comissionado para pintar o famoso pano de boca do Theatro da Paz, confeccionado pelo Atelier Carpezat, ainda existente. Em 1902, retorna ao Brasil seguindo para o Rio de Janeiro. Foi um dos fundadores da revista O Malho, e de outras revistas ilustradas, A Avenida em 1903 e O Pau em 1905. Crispim faleceu em 1911, aos 53 anos, no Rio de Janeiro.

Segundo Vicente Salles (1992), Manoel do Amaral fez sua iniciação artística também no Pará, associado ao irmão. Assim como ele, Manoel recebeu bolsa do Governo Provincial para estudar na Europa. Este foi discípulo de Irineu 
de Souza e auxiliar, como Crispim, de Domenico de Angelis nas obras da Catedral de Belém e do Theatro da Paz. Recebeu de seu irmão, ainda em 1877, a gerência de um jornal consolidado e deu seguimento a sua linha editorial. A dupla já havia adquirido as oficinas de litografia e gravura, instaladas na Rua da Indústria, 3, onde já fora impressa a edição de setembro e gravadores contratados na Europa.

João Archibald Campbell nasceu em Belém em 1840, filho de prósperos comerciantes escoceses estabelecidos na capital. Não seguiu a vocação familiar enveredando pelo jornalismo. Envolveu-se e fundou diferentes jornais, Diário de Notícias, A Tribuna, Gazeta de Notícias e por fim, A República. Envolveu-se com a litografia e o jornalismo ilustrado tardiamente, quando adquiriu, em 1888, a oficina de Amaral e a transfere para a Rua da Trindade, 5. Campbell dá seguimento ao Semana Illustrada, agora com o nome encurtado, A Semana, lançando em abril de 1889. Mantendo o mesmo formato e características, conta com a colaboração de outros artistas, como João Gomes de Faria (Faria), J. Girard, R. Lima, Manuel Amaral (Duc) e Irineu de Souza (Irineu), além dele próprio, que assinava A. Campbell, Campbell ou simplesmente A.C. O pesquisador Vicente Salles acredita ser Campbell o misterioso artista Til que assina ilustrações nas últimas edições da Semana Illustrada. Teoria não confirmada, mas plausível, uma vez que estaria aprendendo a técnica da litografia. Segundo Salles (1992), no ano de 1900 João Campbell era o proprietário do Atelier Campbell, com tipografia, seção de gravuras, fotogravuras, zincografia e litografia, um dos mais importantes do gênero.

Entre os colaboradores da A Semana está João Gomes de Faria, jovem e talentoso artista, nascido em Belém em 1865, que também foi discípulo de Domenico de Angelis em sua passagem por Belém. Em 1891, foi nomeado desenhista da Repartição de Obras Públicas, mas logo, por seu talento, recebeu uma bolsa para estudar na Itália, onde reencontrou e trabalhou com De Angelis. De volta ao Pará, assina diversas ilustrações no A Semana. Faleceu em 1898, aos 33 anos.

Davi Osipovich Widhopff (D. O. Widhopff), ucraniano, nasceu em 1893 e faleceu em 1933. Veio para Belém contratado pelo governo para lecionar desenho na Escola Normal e no Liceu Paraense. Além do ensino se dedicou à pintura, desenho e à caricatura. Executou diversas ilustrações para a imprensa diária, em especial para a Província do Pará, e lançou dois periódicos ilustrados: Zig Zag e 0 Mosquito. Terminado seu contrato, com duração de três anos, retornou a Paris deixando a influência forte de seu estilo.

João Afonso do Nascimento - Angelus, maranhense, torna-se responsável pelo lançamento de $A$ Vida Paraense em 1883, jornal ilustrado e caricato impresso na tipografia Livro do Commercio, com ilustrações litografadas por C. Wiegandt (SALLES, 1992). Outro artista que merece atenção é Nicephoro Moreira, xilógrafo cearense. Encontramos poucos registros de xilógrafos nesta pesquisa; Ignácio Moura, no livro Estado do Pará - Exposição Artística e Industrial de 1895 cita dois artistas, os portugueses George Minchin e Plácido Marques de Oliveira, mas não 
há referências visuais de seus trabalhos. Em relação a Nicephoro, que editava o pasquim O Figarino em sua terra natal, depois reeditado no Pará, encontramos ilustrações na Revista Paraense e, depois, em outras publicações locais. Quanto à versão paraense do Figarino, infelizmente nada foi encontrado. A partir do ano de 1904, encontram-se também xilogravuras de Nicephoro no Jornal do Commercio em Manaus, indicando que o artista circulou na região e sua colaboração foi muito valorizada, uma vez que seu nome é bastante citado por este órgão de imprensa. No mesmo jornal, verifica-se que em 1905 Nicephoro teria viajado mais de uma vez a Lisboa para aprimorar sua arte com um artista citado como "Pastor", mas não interrompe sua colaboração no Jornal do Commercio. Sua morte é relatada na edição de 15 de janeiro de 1925.

Apesar de ser possível citar um número expressivo de artistas ligados à imprensa ilustrada, são poucas as oficinas litográficas que pudemos detectar.

Tabela 1 - Oficinas litográficas que operaram em Belém entre 1870 e 1910.

\begin{tabular}{|c|c|c|c|c|c|c|}
\hline № & Litografia & Endereço & Início & Fim & Impressor & OBS \\
\hline & 1870 & & & & & \\
\hline \multirow[t]{2}{*}{1} & $\begin{array}{l}\text { Lyt de } \\
\text { Wiegandt }\end{array}$ & $\begin{array}{l}\text { Travessa São } \\
\text { Mateus }\end{array}$ & 1871 & 1921 & Wiegandt, diversos & $\begin{array}{l}\text { Depois Gráfica } \\
\text { Amazônia }\end{array}$ \\
\hline & 1880 & & & & & \\
\hline 2 & $\begin{array}{l}\text { Lyt de } \\
\text { Amaral }\end{array}$ & $\begin{array}{l}\text { Travessa da } \\
\text { Indústria, } 3 .\end{array}$ & 1887 & 1888 & $\begin{array}{l}\text { Crispim do Amaral. } \\
\text { Manuel do Amaral }\end{array}$ & \\
\hline \multirow[t]{2}{*}{3} & $\begin{array}{l}\text { Lythographia } \\
\text { Campbell }\end{array}$ & $\begin{array}{l}\text { Rua da } \\
\text { Trindade, } 5\end{array}$ & 1889 & 1905 & $\begin{array}{l}\text { Editor e Litógrafo: } \\
\text { João Campbell }\end{array}$ & $\begin{array}{l}\text { A mesma de } \\
\text { Amaral. }\end{array}$ \\
\hline & 1900 & & & & & \\
\hline 4 & $\begin{array}{l}\text { Arthur } \\
\text { Caccavoni }\end{array}$ & & 1900 & 1900 & Caccavoni & \\
\hline 5 & $\begin{array}{l}\text { Nicephoro } \\
\text { Moreira }\end{array}$ & & $1900 ?$ & & & Xilogravura \\
\hline
\end{tabular}

Fonte: Biblioteca Nacional.

Voltando ao pioneiro Wiegandt, este alcançou grande prestígio. Além de suas atividades na empresa litográfica, foi nomeado professor de desenho na Escola Normal, fez parte de diversas associações culturais e artísticas. Em 1895 a oficina litográfica já era um complexo gráfico-industrial, o Estabelecimento Gráfico C. Wiegandt, atuando em paralelo com uma conceituada empresa de mármores, produzindo esculturas, relevos para a arquitetura e realizando trabalhos de grande porte. Tornou-se um grande empresário.

\section{CONCLUSÃO}

A vinda de Wiegandt a Belém marca uma nova fase para a história gráfica da província, tendo permitido o surgimento da imprensa ilustrada através da litografia e fundamental para o desenvolvimento da indústria gráfica 
local. Não apenas permitiu que a tecnologia se instalasse na província como estimulou, favoreceu o cenário de litógrafos e o surgimento de jornais e revistas ilustrados no Pará.

A litografia foi responsável, acima de tudo, pela possibilidade de se produzir conteúdo impresso que aliava texto e imagens, de forma complementar, criando novas camadas de representação e interpretação. A imagem deixa de ser um marcador gráfico ou uma alegoria, passando a carregar os valores da modernidade, criando um intercâmbio de novos significados.

No Pará, como no resto do mundo a nova sociedade urbana se organiza em torno de ideais de progresso, indústria e civilização. O impresso litografado, na medida que materializava em imagens as notícias, eventos e personagens do momento colabora para essa reconfiguração da vida social, contribui para a construção deste ideário de modernidade. A introdução da litografia, da fotografia e demais avanços técnicos da área gráfica no Pará transformaram a cultura impressa em um dos principais instrumentos de construção de um discurso, utilizado para ampliar e consolidar o imaginário da modernidade da época. Desta forma, os estudos voltados à produção e consumo dos produtos impressos, efêmeros ou não, se revelam com importantes para o entendimento de nossa história.

Por último é preciso lembrar que existem regiões de nosso país que ainda permanecem pouco estudadas e compreendidas. Assim, pesquisas voltadas para o entendimento de suas dinâmicas são fundamentais para o melhor entendimento do desenvolvimento e história do Design no Brasil, e precisam ser estimuladas. 


\section{REFERÊNCIAS}

BIBLIOTECA ARTHUR VIANNA. Disponível em: <http://www.fcp.pa.gov.br/ espacos-culturais/sede/biblioteca-arthur-vianna>. Acesso em: 26 nov. 2013.

BIBLIOTECA NACIONAL DIGITAL BRASIL. Almanak administrativo mercantil e industrial. (PA) - 1868 a 1873. Disponível em: <http://hemerotecadigital. bn.br/acervo-digital/almanak-administrativo-mercantil-industrial/705985>. Acesso em: 26 nov. 2013.

BIBLIOTECA NACIONAL. Disponível em: <https://www.bn.gov.br>. Acesso em: 26 nov. 2013.

BIBLIOTECA PÚBLICA DO ESTADO DO PARÁ. Jornais Paroaras: catálogo. Belém: Secretaria do Estado de Cultura Desportos e Turismo,1985.

CARVALHO, Alfredo. Anais da imprensa periódica pernambucana de1821 a 1908. Rio de Janeiro: Instituto Histórico e Geográfico Brasileiro - IHGB, 1908.

FERREIRA, Orlando da Costa. Imagem e letra: introdução à bibliologia brasileira. A imagem gravada. São Paulo: EDUSP, 1976.

INSTITUTO HISTÓRICO E GEOGRÁFICO BRASILEIRO. Revista do Instituto Histórico e Geográfico Brasileiro. Rio de Janeiro: Imprensa Nacional, 1908. Tomo consagrado à Exposição Commemorativa do Primeiro Centenario da Imprensa Periodica no Brazil, promovida pelo mesmo Instituto.

KNAUSS, Paulo. Introdução. In: KNAUSS, Paulo et al. (Org.). Revistas ilustradas: modos de ler e ver no Segundo Reinado. Rio de Janeiro: Mauad X; FAPERJ, 2011.

MOURA, Ignacio. A exposição artística e industrial do Lyceu Benjamin Constant: Expositores em 1895. Belém, PA: Typografia do Diário Official, 1895.

MUSEU PARAENSE EMÍLIO GOELDI. Boletim. Belém, 1983. (Nova Série Zoologia, n. 123, p. 1-38).

PARÁ. Álbum do Estado do Pará: 1908. Paris: Imprimerie Chaponet, 1908. 
MARTINS, Fernanda de O.; LIMA, Edna Lucia O. da Cunha; LIMA, Guilherme Cunha

SALLES, Vicente. Editoras de música no Pará. Revista Brasileira de Cultura, Rio de Janeiro, ano 4, n. 12, p. 17-36, abr./ jun. 1972.

SALLES, Vicente. João Carlos Wiegandt. Brasília: Microedição do autor, 1994. 